DOI https://doi.org/10.36059/978-966-397-216-9/83-101

\title{
ON THE WAYS OF THE HUMANITIES EVOLUTION BY MEANS OF SYNERGETICS
}

\section{Ovchynnikova A. P.}

\section{INTRODUCTION}

The article considers the history of maturity of the Natural Science and Fundamental Science. Three directions of their evolution were revealed. Two of them are traditional; they have attracted methodologists' attention for a long period of time; their advantages and disadvantages have been well studied. The first one is inductive. This is the most natural and common way of gradual generalizations, unification and systematization of the facts. A scientist, at the end of each stage of the way he follows, hopes to get the empiric laws, which he/she will be able to apply to some other observations that is done to receive the nomologic explanation and correspondent predictions. This way is still open for the development of the Humanities; however, it is not efficient enough. The second way is hypothetical- deductive. There is no hope that in the foreseeable prospective the Humanities - from History and Sociology to Culture studies - will follow this way. The most hopes are linked with the third way which can be called synthetic. Under this term we do not mean the merger of one discipline with another more developed science, or the amalgamation of two disciplines in order to get a kind of a centaur, in which each of them will lose its own specifics.

The issues of sociology, structural linguistics, cognitology, experimental psychology are more or less in accordance with the classical canons of science. However, these disciplines have not been summoned yet to solve the problems of globalization. Here we speak about such disciplines as general sociology, politic studies, culture studies, history, general psychology, pedagogies etc. All these disciplines can be referred to as to science only in the broadened meaning of the word.

\section{Knowledge and Science}

The term "science" initially is always referred to in its "weaker" sense - in case when the knowledge, in the form of the descriptions acquired empirically, is accumulated in the great volume. Then, there comes disciplinary organization of the knowledge and the scientists need 
to turn to classifications. Although, the other requirements that the "strong" science has to correspond with are not yet met by it (for, example, nomologic explanations, as well as the relevant predictions, almost always cause some complications), all the branches of the Humanities are full of descriptions, classifications, and various interpretations of the subjects. Apparently, structuring the models of the subject, together with the particular classifications, to which, beyond one's volition, the objective status is often attributed, - is a sufficient grounding that allows us to call this domain of knowledge "science".

The described way has the disadvantages, typical for any inductive research, as not only do the empiric laws have the probable character, but they are also hard to be verified. Though, the Humanities' subjects are extremely complicated and dynamic, the reliability of the general conclusions made for them is quite low, and the ethical reasons make experimenting on people prohibited. Besides, this way is long, while the success on it is not guaranteed. History, general psychology, pedagogies, sociology, for instance, have existed for more than one thousand years, they continually make some generalizations and classifications, but yet they have not crossed the line which separates the science in the broadened sense of the word from the strong science. Some things that are supposed to be the terms in these types of science, as a rule, do not have generally (commonly) meaningful definitions.

Liberal hypothesizing is possible, but then there come the problems: how to find the empiric verification (proof) or contradiction for such hypothesis? And the way of formalization, or formal confirmation of the hypothesis is, in fact, closed: formalization of the affirmations in the Humanities is hardly ever made.

Such a method is the method of inoculation, when one of the existing theories, corresponding to the classical canons, is used to strengthen one of the Humanities' branches; that theory is considered as a method of the tasks. Natural science has applied this method for long: we should once more recall here how effective application of mathematics in the area of physics was, or think of "physical chemistry" or "chemical physics". There is a similar phenomenon on the border between two disciplines in the sphere of the Humanities. From time to time, there emerge the concepts of historical psychology or political culture, social psychology or social pedagogy etc. However, the problem of adequacy comes to the foreground in this case. Thus, as a rule, in all concepts of this kind the question of relevancy of the method is not raised; the second condition of the adequacy is not completed, we mean the necessary divergence of the 
means of the problems solution. As a result, in the new concepts the indefiniteness of the problem solution is not reduced, but on the contrary, is multiplied by the indefiniteness of the method, by means of which the problem is solved.

The most important internal feature of knowledge is being substantiated. Knowledge cannot be accepted as scientific until its reasoning (substantiation) is declared. That is why the presence of a description is not a characteristic feature of science; at least not until the conditional (implicative) opinion sentences are presented. The implicative of the main facet of knowledge does not mean that any scientific knowledge is knowledge of the reasons. The basis is not always the reason. We should distinguish two pairs of notions: on the one hand, there are ontological notions of the cause and action, on the other hand, logical notions of the basis and consequence. Let us compare the ideas by Aristotle and L. Wittgenstein. Aristotle wrote that we "suppose that we know each object ... when we think that we know the reason for it" ${ }^{1}$. L. Wittgenstein says; "In the law court it would convince no-one if the witness simply declared - 'I know...' It should be proved that the witness had the ability to know" ${ }^{\text {. }}$. Here Wittgenstein clearly considers the reasoning, substantiation not the reason. In fact, we make our judgments on the economy crisis on the basis of the ratings published with regards to some banks and of the financial conditions in the whole state. However, nobody would say, that those data are the reason for the crisis itself. Aristotle in the above mentioned statement speaks of the ontological, but not logical bases of knowledge, e.g. about the knowledge in Physics, not a physician's judgments. Correspondently, knowledge as it is does not yet suppose either the scientific nature of this knowledge, or the ability to make predictions based on it.

We should also mark, that any, even the most exemplary, sphere of science cannot as well do without the affirmations which are accepted with no substantiations. Thus, such are the postulates and scientific principles that are used as the means of substantiation. According to L. Wittgenstein's views, the location of the principle.'? is - "at the

1 Аристотель. Вторая аналитика (l\b 10). (1978). Соч. в 4-х томах. Т. 2. Москва: Мысль, 259.

${ }^{2}$ Витгенштейн, Л. (1994). О достоверности (Д, 441). Философские работы. Ч. 1. Москва: Гнозис, 375. 
bottom" of the knowledge, were the belief reigns ${ }^{3}$. Apart from this immanent feature, the scientific knowledge also has a number of characteristics of the external type, i.e. not deriving from the nature of knowledge as it is. In addition to the above mentioned trait explicitness, that means the feature of being expressed in a particular suggested symbolic form (form of signs), there is one more requirement which the scientific knowledge must meet, - its total significance. This feature implies two ideas. Firstly, generalization (inclusion of all the mentioned phenomena), and, secondly, the maximum possible unambiguous meaning of the expression, - when the core sense of the message could be perceived by everyone, at least, by the competent people, in a more or less similar way, within the realms of their mutually accepted (inter-subjective) ontology. In order to ensure relatively single (unambiguous) meaning in perception of the messages, the special science languages are used.

The general, common meaningfulness of the scientific knowledge, thus, does not suggest the ability to use only the natural language, as well as it does not mean that the scientific text should be understood by all the people. The commonly available culture is presented in the natural language. Scientific information is involved into it as far as and as much as it is connected with the systems of the people's, belonging to this culture, views. Another significant attribute of scientific knowledge is the fact that it is, by the principle, ontological, in the sense of its belonging to some referent, which exists beyond the boundaries of this knowledge. That means that, at least potentially, any knowledge must suppose more or less commonly meaningful ontological interpretation (or a number of the interpretations) based on some objects, attributes or relations (which do not necessarily exist in the physical world, but as it is said, in one of the possible worlds). The attribute of the principally ontological nature of scientific knowledge does not involve any metaphysical solution in the form of accepting the particular "nature" in the domain of interpretation. Moreover, the ontological basis of science is changeable, relative and on every occasion is defined by the functions. When K. Godel was working on the problems of the total formalization in Arithmetic, he used the language of calculation expressions as the meta-language. The subject

${ }^{3}$ Витгенштейн, JI. (1994). О достоверности (Д. 253). Философские работы. Ч. 1. Москва: Гнозис, 353. 
language (Arithmetic) was regarded to be the ontological basis for the consideration. Generally speaking, the multi-level character of knowledge is another attribute of its development and maturity.

It is necessary to note, that application of maths in the humanitarian subjects has been quite restricted, as mathematics, which completes the second condition - of adequacy, fails to meet the first requirement of relevance. Application of the traditional methods of mathematics to sociology has left out unstudied the whole group of problems that deal with a person in particular as well as all the whole complex of globalization issues.

Why, at all, should we strive to turn the Humanities into science according to some classical pattern (model), when science as it is has come to its non-classical (or, as it is said, post non-classical) phase of the development? Thus, the classical patterns of structuring the scientific knowledge have undergone some changes. Perhaps, the Humanities have skipped the classical phase and will acquire their post non-classical status in science at once? Isn't it the fact which is confirmed by the humanities thinkers' attempts to apply their ideas, characteristic for studying the processes of self-organization in nonlineal environment, in order to explain the complex social, ethic, esthetic, and psychological-political processes?

And in the Humanities cognition, in particular, especially in history and psychology, the inevitable significance of randomness is emphasized; the impossibility to predict the future unambiguously is stated. The research on the dissipative structures (Haken, Prigozhin and others) and emergence of the conception called synergetics have only made this tendency stronger. So, the limited nature of classical physics in the description of time irreversibility, which allows us to distinguish past and present, was realized; while this distinctions are really essential for biology, and of course, for description of the social and other humanities' objects.

It was shown that within something which was considered to be chaos (in its classical understanding - a misbalanced systems with non-lineal changes), tiny fluctuations on the micro-level can lead to the changes in the macro-systems, and so become the beginning of the directed evolution (that means, of the new order) ${ }^{4}$.

${ }^{4}$ See a well known work by I. Prigozhin: Пригожин, И., Стенгерс, И. (1986). Порядок из хаоса: Нозый диалог человека с природой. Москва: Прогресс 
(However, the other side of this matter was noticed: when the environment is homogenous, its instability, sustainability to small fluctuations in some cases result in the formation of complicated structures, in other cases - to their destruction) ${ }^{5}$. However, it should be highlighted that the conception of synergetic grew up in the depths of classical science and so, it does not cancel the determinism where there is no chaos in its classic sense, but there is order; as well as it does not cancel the classical scientific methodology in general. Non- classical science did not bring about any principle changes in the requirements to the formation of the strong theory. The methodological alterations affected only the fact that, although science is still aimed on the maximum avoidance of subjectivity, or bias, at any stage of a research it should also limit its requirements of objectivity. Knowledge of the nomen, of the world "as it is", without a person's (individual's) impact on the picture of the world - by means of the ontological prerequisites that are believed in by this individual - is impossible at any phase of the cognitive process. It is particularly what was noticed by I. Kant, who limited the sphere of knowledge by the phenomena.

As knowledge is ontological, it always tends to set some valency, i.e. it requires the answer to the question of the truthfulness/falseness (or some other meanings-depending on the accepted logic of the analysis).The many logical bases that allow us to reveal the valency of different types also confirm the maturity of particular science. Also, it is not supposed that all the statements have their valency. For instance, the performatives (the statements that are at the same time acts, such as "I swear to tell the truth and only the truth",) do not possess any valency at all. There is no use speaking about the valency of such sentences as "The citizens of the state have their right for work, rest and education". Listing the above mentioned features, as it is, points at one more attribute of knowledge: it is possible, in its turn, to possess the knowledge about the knowledge. The knowledge of science is reflexive by the principle, as it supposes the possibility of the self-reference. If there is science, there should by the corresponding meta-science. However, the opposite is impossible: the existence of a meta-science does not confirm the scientific meaning of the knowledge about the object.

5 See Kurdyumov's comments to the article by I. Prigozhin: Пригожин, И. (1991). Философия нестабильности. Вопросы философии, 6, 46-57. 
Finally, scientific knowledge possesses one more essential trait - it is always systematic. A separate simple (elementary) suggestion cannot meet the requirement of the substantiation, so one should turn to some other suggestion, as, to be precise the system of substantiation (reasoning) is needed. We cannot say anything about the valency of the suggestion unless we include it into the system of other suggestions which can say something about the same subject and in the same sense.

To summarize, we should say that in any discipline or any sphere of culture there is knowledge in a narrow as well as in a broad sense, but the knowledge in the broad sense is not sufficient to give an opportunity to speak about the existence of the particular science. So, in which sense is it possible to speak of the knowledge of the Humanities as the scientific knowledge? All the gigantic volume of the texts which were accumulated over the centuries and were attributed to the humanities' knowledge may be divided to the "humane science" (regardless of the term presented in the English language scientific tradition, we will use this phrase so on) and "the humanities". At first, we can distinguish these concepts on the basis of the spheres and ways of description of their referents. The texts of the first type deal with the answers to the question of the society structure, in particular, and of the place and the functions that a person has in the society and the nature. This presents the ontological (objectivist) approach to a person, such approach is typical for scientific knowledge. In this case, at least one of the mentioned requirements to the scientific knowledge is met, so we have the right to speak about the humane science.

On the whole, beginning with F. Schleiermacher and then to W. Dilthey, M. Heidegger, the existentialists and later to the Postmodern philosophy and nomology by G. Deleuze and F. Guattari, the knowledge of the Humanities in the direct or indirect form is opposed to the natural science, referred to by the word science. According to Dilthey, if the scientific knowledge appeals to the nomological explanation of the world (summarizing by some common law), the knowledge of the Humanities tends to imagine and understand the individual (often unique) phenomena. It can be easily proven, that none of the texts of ontological character in the Humanities is free from the subjective intentional descriptions, though there were a lot of attempts to create such "pure" texts.

On the other hand, there are no "pure” Humanities. Unless we express our ideas by means of simply interjections, it is impossible to be absolutely free not only from the rational organization of the text itself, but also from adjusting the descriptions to some general notions. Apart 
from that, if we do not limit the knowledge of the Humanities to the descriptions only, we try to achieve understanding the subject, as it is usually stated (for instance, a person or an object which is named as "the world of life"). In this case the specific function of the Humanities, unlike this of the Science, should be seen in such understanding, comprehension, in particular. However, what is the methodological meaning of this cognitive phenomenon?

Generally speaking, understanding is the universal cognitive operation and, simultaneously, it is the general target. Its aim is to give the sense and meaning to the subject considered. The subject of cognition may be any item - natural or social phenomena, as well as the objects d'art produced by the culture. Due to this reason, understanding (comprehension) can hardly be viewed as the specific procedure in the realm of the Humanities' knowledge. In addition, nothing in the nature, culture or the cognitive process can be understood completely, absolutely. The reason for it is both in the principally unlimited nature of cognition, and in unavoidable hermeneutic circle, when, according to one of the numerous interpretations of this peculiar features of human cognition, the whole cannot be understood prior to the parts of it, and the parts cannot be comprehended without understanding of the whole. Moreover, as it was noticed long ago, any subject allows the existence of plurality (multi-sidedness) of its understanding. Indeed, the results of any cognition are always subjective, personal, as it is the person who (by the use of the signs systems) attributes some senses to the subject (thing) and indicates its meaning. However, the Humanities do not monopolize comprehension, understanding. In fact, the "humanitarians" (that is what we call the Humanities scholars who want to separate their domain from science) went far on the way of describing the subjective character of comprehension. Here is the reconstruction of the text's meaning resulting from its psychological, stylistic and grammatical interpretation (in hermeneutics by F. Schleiermacher); as well as psychological analysis via the notion of empathy (V. Dilthey and others), also the attempts, on the contrary, to free the texts' comprehension analysis from the excessive psychological component through the reference to the logical analysis of the inter-subjective constituent in the consciousness (E. Husserl); turning to the cultural analysis of the discourse of various kinds, their author's and reader's senses.

The desire to attribute some special humanitarian-methodological meaning to the procedure of understanding was followed by its opposition to the procedure of explanation. It was said that understanding, unlike explanation, is comprehension of the unique and 
individual, not the common (J. Droysen, W. Dilthey and others). On the other hand, the attempts to take comprehension procedures beyond the boundaries of the traditional methodology made understanding the basic, impossible to be defined, category of any philosophicanthropological consideration: Heidegger and Gadamer see comprehension (understanding) as the essence of the human existence, the means of self-understanding and selfdeclaration. Hence, the text is viewed as the subject of comprehension; which (text), with regards to the usual, natural use of the word, was understood in a very broad sense: everything, including the nature ("the book of the nature"), is the text. The latter was given its meaning in the cognitive-cultural context due to the ontology which is predetermined by the particular used language.

\section{Synergetics}

The ideas of synergetics are expressed and presented to the judgment of the scientific society via the adequate scientific means. At the same time, it is highlighted that although the time and place, where the points of bifurcation may appear, and then the new order may develop out of chaos, definitely cannot be predicted by means of classical methods; but after such an order emerges, the new system will be described by the traditional language of science. In the prospective, the construction of the synergetic theory supposes its ability to make plausible predictions at least, the meteorologists, who obviously deal with the dissipative structures can make short- term, middle-term and long-term predictions, and we all sometimes trust these predictions.

In other words, the more essential task of synergetics is not the description of how the order emerges from chaos, but the search of the order in the chaos, indeed. Non- classical science does not suggest rejecting the quantities analysis, but it emphasizes the practical difficulties concerning making decisions in the circumstance when one has to deal with the factors the quantity of which is comparable to Avogadro's number (i.e. about 6*1023). Here are some suggestions by I. Prigozhin ${ }^{6}$ : “...for every billion of photons that are being in the chaos there is, at least, one elementary particle which is able to stimulate their transition into the organized structure of this myriad photons...”; “...order and chaos co-exist as two aspects of the one whole and give us

${ }^{6}$ By Prigozhin I., see Пригожин, И. (1991). Философия нестабильности. Вопросы философии, 6, 46-57. 
different visions of the world". And finally: the science of the future, maintaining the analytic accuracy of its -western version, will care about the global, holistic view on the world" ${ }^{7}$. By this, in the most obvious manner, it is supposed that both determinism and classical scientific methodology cannot be left out by the modem science as something unnecessary, they are only limited by what we call the randomness and freedom of choice.

The modem science, despite its entire advancement, has not even started doing the task instead of the Humanities scholars - we mean completing the proper analysis and looking for the instruments suitable for the holistic reproduction of the Humanities' subjects. However, if we agree with the statement that non- classical science has made an important step to come closer to the Humanities, we cannot stop thinking that the Humanities should move forward closer to science, to go their half of the way: the "ball is on the Humanities' half of the pitch". The attempts to plant the ideas of synergetics on the field of the Humanities, which have been quite popular recently, did not bring any fruit, as the second requirement- of the adequacy- was not met. So, nobody succeeded to apply the language of synergetics (the language of non-lineal equations) to the Humanities' subjects.

Turning directly to the conceptual side of the issue - to the synergetic ideology - we can only find out the things which have already been well known. Didn't anyone know before synergetics, that the Humanities researchers were interested in misbalanced as well as balanced systems, in particular? Did not anyone speak of the fact that the use of strict determinism in attempts to explain social and humanitarian problems is not really efficient? Did not anybody notice that fluctuations are typical for purely human systems, including social ones, that chaos turns into order within them (systems), as well as order turns into chaos? Or, maybe, nobody knew that predicting such fluctuations and the character of the future attractors is really complicated? Or that ostensibly unimportant events or circumstances can greatly affect the course of history (should we recall Napoleon feeling unwell before Waterloo battle, or any other similar to it accidents)?

It is highly ineffective to further defend the Humanities' specifics compared to natural science. Generally speaking, it would be quite bizarre, if a Person - facing the Universe and being on his/her own as a

\footnotetext{
${ }^{7}$ Italics - by the author.
} 
part of it - used two different and also opposing methods of cognition. In our opinion, the meeting of the two methodologies is inevitable.

If the most reassuring way to improve the scientific status of the Humanities is the method of inoculation, so the most plausible "substance" the Humanities can be inoculated with should be looked for among the General Science theories. Here we should pay attention to such theories which: would meet two requirements of the method's adequacy, at minimum would be based on the extensional approach to their subjects, and would not exclude synergetic and, in general, nonclassical ideology. No matter how far the Humanities have moved on the way to acquire the classical characteristics of scientific knowledge, the principle of being complementary to the corresponding humanitaristic area will always remain fundamental for it; in particular, when it goes about generalization and individualization. Correspondingly, the nomologic and idiographic approaches, as well as the intentional understanding of the world and ontological component of the view on the world, come forward as supplementary ones. As long as the Humanities and the humane science complement each other they cannot and, perhaps, will never be able to, prove their exclusive nature. At the same time, we suppose to search the ways in which this complementary character can be presented by.

It is obvious, that all the modem crises root in the spiritual crisis, including the spiritual crisis of science, in particular. Is not turning to synergetic a representation of crisis in science which took on too much responsibility, and now it (science) is, apparently, losing its authority? It has been a century since L. Tolstoy said, that science did not only fail to come close to the answers, but had not even stated the most essential for individuals questions - questions of the consciousness and happiness, duty and freedom etc.

Here we should mention J. - P. Sartre, who thought, that philosophy is something different from what the European philosophers of the New Age had been doing. In fact, it (philosophy) starts where science finishes, but not where science still exists. However, at the point where science finishes there is no and even cannot be any answers to the questions about the future. In the discussions of this type we do not usually refer to the pop-art, but at some extent it reflects the state of the "everyday" consciousness. So, as early as in the 80-s a popular group "Sex pistols" created a slogan "There's no future!" and, thus, their concerts gathered thousands of spectators. Nobody - even at that time - believed in the 
happy future. But, in this case we can paraphrase Dostoevsky's sentence and say: if there is no future, nothing is prohibited.

The humanitarians require artistic descriptions and narratives, while the Humanities researchers attempt to find strict descriptions of the events and try to predict at least something.

All this has happened on the background of the events when we witnessed how the unpredicted culture revolution took place and then the new civilization, though, yet not well enough understood, was bom. Not speaking about the phenomenon of books being substituted by the TV, or the cinema being replaced by the Internet, "serious" music - by "pop" etc., and the most essential issue here is the fact that the new generation of young people with "the video consciousness" was bom. Youngsters are excellent at acquiring visual information; they "digest" it much more successfully and in much greater quantities than the previous generations. At the same time, a great number of young people, even ones who got higher education, merely get stuck when they deal with written text and are not capable of creating a coherent opinion writing, as long as at least five pages. We can complain about it and, following U. Eco, bitterly re-state "that the Middle Ages have started", but the fact is still the fact. Nobody can say whether it is the progress or, on the contrary, the regression of the civilization, - we are not to understand it. Perhaps, the upcoming generation simply will not need the notions that people supposed to be vital during the previous two thousand years, -the coherence and clarity of the ideas, logic and proofs. All of the mentioned will be, for instance, left for the portable computer, which has already become an inescapable part of everybody's life, like a pen, for example, used to be. And will there be anything that will stop them from implanting such a computer into a person's body?

It is likely that after the collapse of the two-three thousand year old scientific-book civilization people will leave for themselves only one function - to solve problems by means of intuition - it is the only thing which is not available for computers. A well-known mathematician Van Hao confessed that, as a child, he simply "saw" the solutions of the mathematic problems without knowing exactly how he got the correct answers. N.Tesla also noted that he somehow saw the solutions for the engineering tasks; that those solutions came to him from "somewhere above (heaven)". From the modem “intelligent person's” point of view, it is seen that Homo sapiens is transforming into someone new, unknown before, but... But, what kinds of attitude will the people of the globalized future - Homo Novus, - will have to it? 
However, we cannot stop thinking about the following: Is it possible to make a person refuse to understand, analyze the days of yesterday, today or tomorrow? Let us leave all the attempts to comprehend our own selves in our world. This Homo Novus of the future will not even be a Homo. What if some of the humanitarians decide to step on the "stone" of science in the uncertain "swamp" of our perception of the world? Why don't they try to say something really clever, but not too elaborately clever, - about a human being - using the language of science, not of poetry? Eventually, nobody urges the humanitarians to reject a "free floating of a thought”?

A. Pushkin once said: "Why should one try to bite the nurturing breast? Only because the teeth have just come out?" Here we mean that if some universal catastrophe happens the next day, we all will turn to scientists in search of advice on how we should live then. Also, we can recollect Dostoevsky's lines. In “The Adolescent” a 20-year old Arcady Dolgoruky says: “... It is also good to say some nonsense. What did I tell Lambert about the principles? I said, that there are no general principles, but there -are only particular cases; I told him lies, the grand lies! And on purpose, in order to show off! I am a bit ashamed, but it is not important -1 will make it up. Don't be ashamed, Arcady Makarovich. I do like you, Arcady Makarovich. I like you indeed, my young friend. It is such a pity that you are a little liar..."8.

Despite his refusal to make predictions, he described such a believable, plausible picture of our future, that it really urges us to change the whole system of education! Why don't we cut the number of Maths and Physics classes in the schools curricula; introduce the classes in design, commercials' analysis or pop-music! Or, what if one could ask the physiologists to "switch off' children's left-brain thinking at all? Why not to let them use only images in their thinking process, the same as artists do? In this case we may get the emotional-intellectual symbiosis of a human being and a computer!

Such nomologic considerations will always be only the opinion, not the knowledge. Why do not we think in another way? The civilizations develop in an uneven, irregular way that is why in any of them there are both the main, central, and marginal cultures. So, after the Ancient Greeks, the next peak of interest to Mathematics and other abstract branches of science took place only at the New Age. Here we can see the

${ }^{8}$ By F. Dostoevsky. Достоевский, Ф. М. Подросток, 4.III. Гл. 6. 
sufficient grounding to suppose that now we experience the decline of interest to science (besides, not to science in general, but only to the fundamental research). But as the time passes, a century, fifty or even a thousand years later, and the intellectuals (maybe even the humanitarians), not the pop-singers or Hollywood film celebrities, will make it big, will become the most recognized and respected people in the society. Generally speaking, we should admit that futurology still remains the area of competitions in making the more or less believable and impressive pictures of our future.

I suppose, there are no children or parents who would agree to have their left-brain thinking "switched off'. And hardly ever there can be a case when it will become necessary. However, the fact that pedagogies, formed within the previous centuries, becomes an anachronism in the conditions of exponential increase in the pace of technical progress and globalization, is undoubted. Transformation of a computer into a person's everyday companion, as common as a ball-point pen or a pencil, - is revolution, not less essential than the changes which once Guttenberg's ideas brought. So, nowadays the principles on which modern pedagogies is based should also be different.

Humane science attempts to, definitely, in a maximally unambiguous way, identify a person's place in the system of life of the society; however, it leaves the humane essence - the people's intentions, undefined. On the contrary, for the non-scientific humanitarian knowledge, the intentional impulses are important, it fixes them (impulses) as the defined ones, but at the same time the social fate of a person is left unidentified.

It would seem possible now to say that the humane science in particular corresponds to the notion of science, meaning actually science. Indeed, it should ensure the most vital functions of knowledge explanation and prediction.

Alas, here we face the ambiguity of the notion of "science" as it is. It is implied, that there are at least two images of science. Firstly, it is the "strong" science, which means science in the strictly direct meaning of the word. It is the gathering of knowledge in the narrow understanding of the word "knowledge", also it produces the knowledge. Secondly, it is "simply" science (no-one would like to speak of any science as "the week one"!). Here it goes about science in the wide sense of the word.

However, we cannot ignore the methodological weakness of the Humanities knowledge as the whole. In particular, the methodological issues of what we do, i.e. which cognitive procedures (methods) we turn 
to when we comprehend, what is the grounding that allows us to consider that in some cases comprehension (understanding) was completed, and what makes it different from "not understanding". And then: how do we distinguish "good" understanding from "bad" understanding, how is any ranging possible in this case? Finally, why do we with equal ease speak of understanding the nature and understanding a person?

It is remarkable, that all the authors, without any exceptions, while speaking about the achievement of understanding, have always declared that as its result the subject should be presented as the whole (the one). However, the essence of this whole was left out by the analysis, as if the meaning of a word was unambiguous. Meanwhile, a word, often said "accidentally", not "on purpose", is meaningful and is able to dramatically change the sense of the problem that is being discussed. The matter is that everyone who tries to understand something (no matter, whether it is a text or a physical item) implicitly suggests that we perceive the subject in parts, and the connection between the parts of the whole is suggested. It is absolutely clear, that such an implicit suggestion at once leads us to the ontological dimension, and so brings the conclusions, we come to, close to the scientific (belonging to science) result.

It reveals the fact, that all the intentions for objectivity and ontological prerequisites are unavoidable in any humanitarian comprehension in the principle; also we can speak of the supplementary (complementary) nature of the humane science and the Humanities.

\section{Systematic analysis}

Let us think that the strong science it is the domain of knowledge which consists of the strong theories. These theories are organized not only on the basis of some particular ontology, commonly accepted principles and fundamental ideas, in such a way that they altogether could guaranty relatively integrated image of some object, its comprehension. The strong theory necessarily contains some means of confirmation or/ and contradiction to its own affirmations, it is what is called verification or falsification, and what is aimed on the explanation of the origin, structural features or dynamics of the subject, viewing it through the prism of the common laws and regulations (nomologic explanation), or through the common scheme (paradigm or pattern) of the problem solution. In the strong science explanation can also deal with the purposefulness of the subject's conduct. However, only in the case when prior to this, it is defined that the subject implies 
some ontological aims (purpose). Teleo- logical explanation in such a case acquires its obligatory and commonly meaningful character. Thanks to the existence of explanations the strong science should reveal its ability to foresee (predict) ${ }^{9}$.

As the good method we consider not simply the means but the rationally controlled way of the cognitive activity organization. The method in science is a clear and apparent instruction on the consequence of the operations which are necessary in order to get the result without breaking the rules of the accepted logic. Method is something that can be reproduced: any other researcher should have an opportunity to control the results that he got by means of the same method.

Adequacy of the scientific method can be confirmed if two conditions are fulfilled. To become a mean of the impact on the subject researched, the method should, firstly, be relevant, i.e. it should be suitable, appropriate, according to the sense of the task which it is applied to.

Secondly, the adequate method should be divergent, which means that it must be different from the problem by means applied to present the task that is dealt with. In general, if the task, for instance, is of the theoretic nature, it is expected that for its ultimate completion it is necessary to apply the empiric means. And on the contrary, the empiric problem can be considered in the theoretic sphere.

It is obvious, that the empiric problems can often be solved by the empiric means; however, in this case this empiric means should be altered. If not, the solution can be successfully found either accidentally, fortuitously or by the way of experiments and errors. The above mentioned, if it is not rationally organized and purposeful, can only be called a method in the wider sense of the word ${ }^{10}$. The theoretical tasks are often completed via the theoretic means but always with the help of the different theoretic means, the means of the different theoretic

${ }^{9}$ That is what, for instance, D. Hofstadter thinks (see: Douglas, R. (1979). Hofstadter. Godel, Escher, Bach: an Eternal Golden Braid. New York, Basic Books; на рус. яз. - (2001). Гёдель, Эшер, Бах: эта бесконечная гирлянда. Самара: Изд. Дом «Бахрах-M», 295-317). He speaks of an anthill as the whole (not an individual ant separately) as a purposeful acting system, he even created a special character - Ant Hill.

${ }^{10}$ When C. Popper said that the method of experiments and errors (mistakes) is almost the main in science he intentionally emphasized that it was about the empiric confirmation / contradiction of the theory. He noticed, that observations are rarely accidental as they are made with some particular purpose: to verify some theory to get, if it is possible, it's crucial/fundamental contradiction. 
language. The unbelievable effectiveness of mathematics while solving the problems of physics, technology or even some issues of the Humane subjects is possible because of the fact that mathematics presupposes the different languages - provided the first condition of the adequacy is completed - its relevancy, appropriateness for its sense. Alchemists became real chemists only when they succeeded in their science by means of the special language. The comparison to with the process of translation into the foreign languages is suitable here: if someone decided to translate, say, an English book into English again, it would not be the translation, it would be editing.

A lot of people pay attention to the importance of the systematic methodology for the Humanities. So, D. Easton, K. Deutsch and A.A. Davydov ${ }^{11}$ spoke about its application in sociology and politic studies. Davydov, in particular, complained that modern sociology is an out-side discipline, which is the state of crisis and whose future does not give any hopes. He saw the way out in the determination to use systematic methodology. And the problem that should be solved was seen by Davydov in the fact that the majority of the theories lean on the quantitative methods, which are suitable for studying the repetitive phenomena, while sociology deals with the unique phenomena, presented by their qualitative characteristics. In fact, in the search of an adequate method Davydov came up with the theories... which try to restrict the qualitative characteristics to the quantitative descriptions. It seems that particularly quantitative methods brought science the great success. However, one should look for the methods among the conceptions which go in the opposite direction, i.e. which try to present the quantitative characteristics as the qualitative ones. The difference will be clear if we take into consideration the ideas which are discussed in one of the works on philosophy. There it is said that qualitative characteristics are the ones each component of which can be attributed to the subject as a whole, while the same cannot be said of its quantitative components ${ }^{12}$. For example, if we say referring to the author of the "systematic sociology" conception that he is intelligent, and take his

${ }^{11} \mathrm{See}:$ Истон Д. Категории системного анализа политики. $<$ http:www.politnauka.org/library/teoria/iston.php>; Deutsch, K.W. The nerves of government: models of political communication and control. <http:www.garfield. library.upenn.edu/classicsl986/A1986C096500001.pdf>; Давыдов, А.А. (2006). Системная социология - социология XXI века? Социс. 6.

${ }^{12}$ Seе: Уёмов, А.И. (2010). Метафизика: учебное пособие. Одесса: Астропринт, 74. 
wit, insight, ability of a good guess, of foreseeing, tolerance to the opponents etc. as the components of intelligence, we can attribute any of the mentioned components to sociologist A. Davydov in general. Though, we cannot state the same about such components of his characteristics as his particular height, weight or age.

It is also stated that any particular understanding (interpretation) allows some other understanding; there are no objects which can be understood only in one and the only way. Thus, this means that it is necessary to rely on such a systematic method that not only allows but also suggests a possibility of a different understanding of any object. And taking into consideration that the Humanities find differentiating levels of understanding essential, we cannot see any other way to reasonably distinguish these levels than to use systematic analysis. Without systematic presentation of the object, and knowledge in general, it is impossible to "measure, weigh" understanding in other aspects, - in particular, to study its depth and width.

\section{CONCLUSION}

The Humanities researchers, unlike scientists, are mainly aimed at the description of the unique phenomena. However, here we cannot do without the definition of the notion of "uniqueness", i.e. without turning the word of natural language to the term of science. And as a term the word "uniqueness" is used only in the systems theory where, by the way, appears possibility to distinguish the types of the unique. As the terms of systemology some other notions are also defined; without them the scientific work in the domain of the Humanities is hardly possible; they are such notions as "autonomy”, “stability”, "reliability”, “model”, "regeneration”, “isomorphism” and others.

\section{SUMMARY}

So, the good method in science is the purposeful, determined, rationally controlled aggregate of operations that are aimed on the completion of the cognitive tasks. These operations should be adequate (relevant and divergent) to the tasks themselves. A method implies a particular sequence of actions which gives an opportunity of its reproduction to the others who use this method. The rational character of a method means, particularly, that the knowledge about the method is the scientific knowledge itself. From this we may conclude that a method should possess all the features of knowledge, thus, the possibility to confirm (verify) or contradict to the results derived from its application. 


\section{REFERENCES}

1. Davydov, A.A. (2006). Sistemnaja sociologija - sociologija XXI veka? Socis, 6.

2. Deutsch, K.W. The nerves of government: models of political communication and control. <http:www.garfield.library.upenn.edu/ classicsl986/A1986C096500001.pdi>.

3. Dostoevskij, F. M. Podrostok, CH. Ill, Gl. 6.

4. Iston D. Kategorii sistemnogo analiza politiki. <http:www.politnauka.org/library/teoria/iston.php>.

5. Prigozhin, I. (1991). Filosofija nestabil'nosti. Voprosy filosofii, 6, 46-57.

6. Prigozhin, I., Stengers, I. (1986). Porjadok iz khaosa: Novyj dialog cheloveka sprirodoj. Moskva: Progress.

7. Ujemov, A.I. (2010). Metafizika: uchebnoe posobie. Odessa: Astroprint.

Information about the author:

Ovchynnikova A. P.,

Doctor of Arts, Professor, the head of Art and liberal arts department

International Humanitarian University 33, Fontanska Road St., Odessa, 65009, Ukraine 